\begin{tabular}{|c|l|}
\hline Title & Fatigue Crack Growth A nalysis of Fiber Reinforced Concrete with Effect of Interfacial Bond Degradation \\
\hline Author(s) & Li, Victor C.; Matsumoto, Takashi \\
\hline Citation & $\begin{array}{l}\text { Cement and Concrete Composites, 20(5), 339-351 } \\
\text { https://doi.org/40.1016/S0958-9465(98)00010-9 }\end{array}$ \\
\hline Issue Date & 1998_10 \\
\hline Doc URL & http://hdl.handle.net/2115/45599 \\
\hline Type & article (author version) \\
\hline File Information & ccc20_339-351.pdf \\
\hline
\end{tabular}

Instructions for use 


\title{
Fatigue Crack Growth Analysis of Fiber Reinforced Concrete with Effect of Interfacial Bond Degradation
}

\author{
Victor C. Li and Takashi Matsumoto \\ Advanced Civil Engineering Materials Research Laboratory, \\ Department of Civil and Environmental Engineering, \\ University of Michigan, MI 48109-2125, U.S.A.
}

\begin{abstract}
This paper presents an analytic model for fatigue crack life prediction in fiber reinforced concrete (FRC). The model elucidates fatigue crack growth in cementitious matrix material under the influence of external cyclic load and fiber and aggregate bridging. It is shown that fiber-matrix interface damage is necessary to properly simulate the three experimentally observed stages of matrix crack growth, involving a decelerated stage, a steady state stage, and an accelerated stage towards final fracture failure. This model, which explicitly accounts for the positive role of fiber on fatigue life, predicts the existence of the well known fatigue limit load in standard S-N curve tests of FRCs. The basic framework of this analysis can be used to address fatigue life of FRC structures subjected to high cycle fatigue loading, as well as providing a basis for material design of fatigue resistant FRC at the microstructure level.
\end{abstract}

\section{Introduction}

Fatigue life of fiber reinforced concrete (FRC) is attracting significant attention for two reasons. First, FRCs are finding increasing use for applications such as road slabs, bridge overlays, tunnel linings, roofing tiles, and architectural wall panels where their remarkable 
short-term properties are advantageous. Second, civil infrastructures constructed decades ago are now deteriorating with increasing speed. At the time of construction, long-term durabilities were expected, but this has not been fully achieved. Deterioration of highly developed civil infrastructures causes many problems in our society, and a huge cost is required to maintain them. We would prefer to avoid such deterioration with materials used today, including FRCs. Therefore, the increasing use of FRCs requires both low life-cycle cost and high long-term durabilities, primarily measured as a long fatigue life in those applications where high cycle fatigue loading is expected. The importance of fatigue life necessitates a theoretical model that is capable of both predicting the fatigue life for a given FRC structure and designing an FRC material for a given fatigue life.

However, a theoretical prediction/design model has not been developed for fatigue life of FRCs. Fatigue life prediction/design of FRCs has been done mainly via an empirical approach so far. This approach requires time-consuming experimental data collection for a broad range of design cases followed by a statistical analysis which, in principle, is not applicable to other design cases. A theoretical model has to be developed for the above reasons, and such a prediction/design model has to be expressed explicitly in terms of microstructural parameters which govern fatigue behavior of FRCs.

A theoretical prediction/design model for fatigue life is developed in this paper. The theoretical model is based on the micromechanics of fiber bridging in short fiber reinforced brittle matrix composites and predicts fatigue crack growth, which is responsible for fatigue life of FRCs. The effects of microstructural parameters (for example, fiber length, fiber diameter, fiber modulus, fiber volume fraction, and interfacial bond strength) on fatigue crack growth can be examined. Fatigue crack growth for short fiber composites is 
simulated with the following three factors. First, fatigue crack growth in a matrix is related to crack tip stress intensity factor amplitude with the Paris law. Second, the contribution of crack bridging to the crack tip stress intensity factor amplitude is examined using a cyclic constitutive law for the relation between crack bridging stress amplitude and crack opening displacement amplitude. Finally, the influence of frictional bond degradation at fibermatrix interface during repeated load cycles is introduced. This influence is assumed to be governed by accumulated crack opening displacement change. The resulting model simulation is compared to a fatigue crack growth experiment of an FRC subjected to flexural cyclic loads. The comparative results are encouraging. This theoretical simulation successfully reproduces the three stages of fatigue crack growth and also reveals the importance of interfacial frictional bond degradation.

\section{Fatigue Crack Growth Model of FRCs}

\section{Fatigue Damage on Material Constituents}

Progressive fatigue damage on material constituents is responsible for fatigue life of a material. The fatigue damage in FRCs must be quantified for the development of a micromechanics-based model. Here, material constituents include matrix, fibers, and fibermatrix interface, and these undergo microscopic changes during fatigue loading. Some of the microscopic changes in turn cause a detrimental change in macroscopic material properties. For example, the development of microcracks in concrete is supposed to decrease concrete elastic modulus, whereas it is supposed to increase concrete fracture toughness. ${ }^{1-3}$ Among a number of microscopic changes during fatigue loading, fatigue crack growth can be considered the damage most responsible for fatigue life of FRCs and, therefore, must be focused on. FRCs fail in fatigue when a fracture propagates unstably 
subsequent to stable crack growth under fatigue loading. ${ }^{4,5}$ Thus, fatigue life of FRCs is controlled by fatigue crack growth behavior.

Fatigue crack growth in FRCs is affected by three main factors: matrix fatigue crack growth law specific to a matrix, crack bridging by fibers, and fatigue damage in fibermatrix interface and/or bridging fibers. These three factors are discussed in the following sections. First, matrix fatigue crack growth is quantified with the Paris law, which relates the crack growth rate to the crack tip stress intensity factor amplitude. Second, a cyclic constitutive law between the crack bridging stress amplitude and the crack opening displacement amplitude due to fibers and aggregates is described. With the cyclic constitutive law, the crack tip stress intensity factor amplitude, which is reduced by crack bridging, can be evaluated. Finally, the interfacial frictional bond degradation under cyclic sliding is quantified assuming that the bond degradation is governed by the accumulated crack opening displacement change.

\section{Fatigue Damage on Matrix: Fatigue Crack Growth}

Fatigue crack growth has been observed to obey a Paris law type equation for metals, ceramics, and concrete. ${ }^{6-19}$ The Paris law gives the relation between the crack growth rate and the crack tip stress intensity factor amplitude, namely

$$
\frac{\mathrm{da}}{\mathrm{dN}}=\mathrm{C}\left(\Delta \mathrm{K}_{\text {tip }}\right)^{\mathrm{n}}
$$

where a $=$ crack length, $\mathrm{N}=$ number of load cycles, $\mathrm{C}=$ Paris constant, $\Delta \mathrm{K}_{\text {tip }}=$ crack tip stress intensity factor amplitude, and $\mathrm{n}=$ Paris constant.$^{20}$ Then, fatigue life, $\mathrm{N}_{\mathrm{f}}$, is obtained by 
$N_{f}=\int_{a_{i}}^{a_{f}} \frac{1}{C\left(\Delta K_{\text {tip }}\right)^{n}} d a$

where $a_{i}=$ initial crack length and $a_{\mathrm{f}}=$ final crack length. In this model, the aggregates are viewed as bridging elements co-existing with the fibers, so that the cement paste serves as the brittle matrix in FRC composites. Assuming linear elastic fracture mechanics for simplicity, $\mathrm{a}_{\mathrm{f}}$, is related to the cement fracture toughness, $\mathrm{K}_{\mathrm{c}}$, by

$\mathrm{K}_{\mathrm{c}}=\sigma_{\max } \mathrm{F} \sqrt{\pi \mathrm{a}_{\mathrm{f}}}$

where $\sigma_{\max }=$ maximum applied stress in a given load amplitude and $\mathrm{F}=$ dimensionless correction factor, which is a function of body geometry, loading mode, and crack configuration.

Therefore, the problem reduces to obtaining $\Delta \mathrm{K}_{\text {tip }}$ of FRCs. The crack tip stress intensity factor amplitude of fiber composites is attributed to external applied loading and crack bridging, so $\Delta \mathrm{K}_{\text {tip }}$ can be divided into two terms:

$\Delta \mathrm{K}_{\text {tip }}=\Delta \mathrm{K}_{\mathrm{a}}+\Delta \mathrm{K}_{\mathrm{b}}$

where $\Delta K_{a}=$ stress intensity factor amplitude due to external applied loading and $\Delta K_{b}=$ stress intensity factor amplitude due to crack bridging (see Figure 1). $\Delta \mathrm{K}_{\mathrm{a}}$ is a function of body geometry, loading mode, and crack configuration and, for a beam in flexural bending that has a crack on the tension face, is given by 
$\Delta \mathrm{K}_{\mathrm{a}}=2 \int_{0}^{\mathrm{a}} \mathrm{G}(\mathrm{x}, \mathrm{a}, \mathrm{w}) \Delta \sigma_{\mathrm{a}}(\mathrm{x}) \mathrm{dx}$

where $\mathrm{w}=$ beam depth, $\Delta \sigma_{\mathrm{a}}(\mathrm{x})=\Delta \sigma_{\mathrm{o}}(1-2 \mathrm{x} / \mathrm{w})$ (linear gradient for bending), $\Delta \sigma_{\mathrm{o}}=$ applied external stress amplitude, and $\mathrm{x}$ is measured from the tension face of the beam. ${ }^{21,22} \Delta \sigma_{\mathrm{o}}$ is related to applied external moment amplitude, $\Delta \mathrm{M}$, through

$\Delta \sigma_{\mathrm{o}}=\frac{6 \Delta \mathrm{M}}{\mathrm{bw}^{2}}$

where $b=$ beam width. $G(x, a, w)$ is a weight function that represents a unit force contribution to the crack tip stress intensity factor, as follows:

$\mathrm{G}(\mathrm{x}, \mathrm{a}, \mathrm{w})=\frac{1}{\sqrt{\pi \mathrm{a}}} \frac{\mathrm{h}_{1}(\mathrm{x} / \mathrm{a}, \mathrm{a} / \mathrm{w})}{\left(1-\mathrm{x}^{2} / \mathrm{a}^{2}\right)^{1 / 2}}$

where $\mathrm{h}_{1}$ is found in $\mathrm{Tada}^{21}$ and Cox and Marshall ${ }^{22}$.

Similarly, $\Delta \mathrm{K}_{\mathrm{b}}$ is a function of the relation between the crack bridging stress amplitude, $\Delta \sigma_{\mathrm{b}}$, and the crack opening displacement amplitude, $\Delta \delta$, (hereafter referred to as the cyclic constitutive law) and is given by

$$
\Delta \mathrm{K}_{\mathrm{b}}=-2 \int_{0}^{\mathrm{a}} \mathrm{G}(\mathrm{x}, \mathrm{a}, \mathrm{w}) \Delta \sigma_{\mathrm{b}}(\Delta \delta(\mathrm{x})) \mathrm{dx}
$$


where $\Delta \sigma_{\mathrm{b}}(\Delta \delta)=$ cyclic constitutive law and $\Delta \delta(\mathrm{x})=$ crack opening displacement amplitude at a point, $\mathrm{x}$, on the crack surface.

$\Delta \mathrm{K}_{\text {tip }}$ can be calculated as described above, given a body geometry, a loading mode, a crack configuration, and a cyclic constitutive law, if the crack opening displacement amplitude at a point, $\mathrm{x}$, on the crack surface, $\Delta \delta(\mathrm{x})$, is known a priori. The crack opening displacement amplitude at each point on the crack surface can be obtained by solving an integral equation:

$\frac{\Delta \delta(x)}{2}=\frac{4}{E} \int_{x}^{a}\left\{\int_{0}^{a^{\prime}} G\left(x^{\prime}, a^{\prime}, w\right)\left[\Delta \sigma_{a}\left(x^{\prime}\right)-\Delta \sigma_{b}\left(\Delta \delta\left(x^{\prime}\right)\right)\right] d x^{\prime}\right\} \delta\left(x, a^{\prime}, w\right) d a^{\prime}$

where $E=$ matrix modulus. A self-consistent solution for the crack profile change is obtained by numerically solving the integral equation. Details on the numerical scheme can be found in Cox and Marshall. ${ }^{22}$

\section{Effect of Crack Bridging: Cyclic Constitutive Law}

Crack bridging stress in FRCs is exerted by fibers and aggregates, so the cyclic constitutive law of FRCs can be obtained by the superposition of crack bridging stress-crack opening displacement relations due to fibers and aggregates under cyclic loading. A cyclic constitutive law due to fibers and one due to aggregates are briefly discussed here.

The cyclic constitutive law due to fibers is derived based on the micromechanics of fiber bridging. Load amplitude, $\Delta \mathrm{P}$, - crack opening displacement amplitude, $\Delta \delta$, relation for a single fiber is obtained, then the fiber bridging stress amplitude, $\Delta \sigma_{f}$, - crack opening 
displacement amplitude, $\Delta \delta$, relation can be derived by integrating the load carried by individual single fibers with the assumption of 3-D random distribution of the fibers. Expression of $\Delta \sigma_{\mathrm{f}}(\Delta \delta)$ is summarized in Appendix I, and more details of $\Delta \sigma_{\mathrm{f}}(\Delta \delta)$ can be found in $\mathrm{Wu}$ et al. ${ }^{23}$ and Matsumoto and $\mathrm{Li}^{24}$. The resulting cyclic constitutive law can be represented by a normalized form:

$\Delta \tilde{\sigma}_{\mathrm{f}}=$ function $\left(\Delta \tilde{\delta}, \tilde{\delta}_{\max }, \tilde{\delta}^{*}\right)$

where $\Delta \tilde{\sigma}_{\mathrm{f}}=\Delta \sigma_{\mathrm{f}} / \sigma_{\mathrm{o}}, \quad \sigma_{\mathrm{o}}=\mathrm{V}_{\mathrm{f}} \tau\left(\mathrm{L}_{\mathrm{f}} / \mathrm{d}_{\mathrm{f}}\right) / 2, \mathrm{~V}_{\mathrm{f}}=$ fiber volume fraction, $\tau=$ interfacial frictional bond strength, $\mathrm{L}_{\mathrm{f}}=$ fiber length, $\mathrm{d}_{\mathrm{f}}=$ fiber diameter, $\Delta \tilde{\delta}=\Delta \delta /\left(\mathrm{L}_{\mathrm{f}} / 2\right)$, $\tilde{\delta}_{\max }=\delta_{\max } /\left(\mathrm{L}_{\mathrm{f}} / 2\right), \tilde{\delta}^{*}=\delta^{*} /\left(\mathrm{L}_{\mathrm{f}} / 2\right)=\left(2 \tau \mathrm{L}_{\mathrm{f}}\right) /\left(\mathrm{E}_{\mathrm{f}} \mathrm{d}_{\mathrm{f}}\right)$, and $\mathrm{E}_{\mathrm{f}}=$ fiber modulus.

The complete form of (10) is given by (I 3), (I 6), and (I 7) in Appendix I. The law shows that the fiber bridging stress amplitude, $\Delta \sigma_{\mathrm{f}}$, is a function of the maximum bridging strength, $\sigma_{0}$, the crack opening displacement amplitude, $\Delta \delta$, the maximum crack opening displacement experienced in the preceding load cycle, $\delta_{\max }$, and the fiber composite system parameter, $\delta^{*}$. The dependence on the maximum crack opening displacement, $\delta_{\max }$, appears because the debonded length of the fiber-matrix interface and the reduced number of bridging fibers are determined by $\delta_{\max }$, in other words, pull-out loading. The parameters, $\sigma_{\mathrm{o}}$ and $\delta^{*}$, enable us to examine the effects of microstructural parameters on the constitutive law which, in turn, is related to fatigue crack growth.

The monotonic constitutive law due to fibers is required for the evaluation of the cyclic constitutive law since $\delta_{\max }$ is related to the maximum bridging stress, $\sigma_{\mathrm{f} \max }$, experienced in 
the preceding load cycle. The monotonic constitutive law between the fiber bridging stress, $\sigma_{\mathrm{f}}$, and the crack opening displacement, $\delta$, has been derived by $\mathrm{Li}^{25}{ }^{25}$ Expressions of $\sigma_{\mathrm{f}}(\delta)$ for pre-peak and post-peak are summarized in Appendix I.

Normalized curves of fiber bridging stress-crack opening displacement relation for a short fiber composite with $\tilde{\delta}^{*}=0.002$ are shown in Figures 2 and 3 for pre-peak and post-peak respectively. Note that $\delta=\delta_{\max }-\Delta \delta$ and $\sigma_{\mathrm{f}}=\sigma_{\mathrm{f} \max }-\Delta \sigma_{\mathrm{f}}$ in the unloading curves where the unloading occurs at $\left(\delta_{\max }, \sigma_{\mathrm{f} \max }\right)$.

As for the cyclic response of aggregate bridging in tension, some models have been proposed. ${ }^{26,27}$ These are not constructed with physical microstructural parameters, but are based on experimental observations. Due to the lack of a physical model, the cyclic constitutive law due to aggregates is modeled with a simple assumption based on the monotonic constitutive law due to aggregates. ${ }^{28}$ This empirical model fits a wide range of experimental data. For the cyclic constitutive law, the aggregate bridging stress, $\sigma_{\mathrm{m}}$, and the crack opening displacement, $\delta$, are assumed to decrease to zero when unloading occurs. Thus, no crack opening displacement remains when the full unloading to zero occurs. Expressions of $\sigma_{\mathrm{m}}(\delta)$ and $\Delta \sigma_{\mathrm{m}}(\Delta \delta)$ are summarized in Appendix II. Normalized curves of aggregate bridging stress-crack opening displacement relation are shown in Figure 4.

The overall cyclic constitutive law, $\Delta \sigma_{\mathrm{b}}(\Delta \delta)$, as well as the overall monotonic constitutive law, $\sigma_{\mathrm{b}}(\delta)$, for FRCs can be obtained by the superposition of fiber and aggregate bridging stress-crack opening displacement relations. The resulting constitutive law, $\Delta \sigma_{\mathrm{b}}(\Delta \delta)$, is substituted into (8), and the crack tip shielding effect due to bridging fibers on the fatigue crack growth rate can be computed via (1). 
Fatigue Damage on Fibers: Interfacial Bond Degradation

Degradation of interfacial bond strength is focused on in this paper. Interfacial degradation under cyclic loading is suggested by experimental observations in fiber reinforced ceramic $^{29}$ and fiber reinforced concrete ${ }^{30}$. Interfacial frictional bond degradation seems more reasonable for a composite with pull-out (frictional bond-controlled interface) of (shorter) fibers, whereas fatigue fracture of fibers is more reasonable for a composite with rupture (chemical bond-controlled interface) of (longer) fibers or with high stress amplitude conditions. $^{31}$

Following Matsumoto and $\mathrm{Li}^{24}$ a bilinear function for interfacial frictional bond strength, $\tau$, is assumed:

$\tau=\max$ of $\left\{\begin{array}{l}\tau_{\mathrm{i}}+\mathrm{a} \sum_{\mathrm{i}=1}^{\mathrm{N}} \Delta \delta_{\mathrm{i}} \\ \tau_{\mathrm{f}}\end{array}\right.$

where $\tau_{\mathrm{i}}=$ initial bond strength, $\mathrm{a}=$ degradation coefficient (negative for degradation), $\mathrm{N}=$ number of load cycles, $\Delta \delta_{\mathrm{i}}=$ crack opening displacement change at $\mathrm{i}$-th cycle, and $\tau_{\mathrm{f}}=$ final or steady state bond strength. Here, the interfacial bond degradation is measured with

$\sum_{i=1}^{\mathrm{N}} \Delta \delta_{\mathrm{i}}=$ accumulated crack opening displacement change.

The interfacial frictional bond strength then degrades (a is negative) with the accumulated crack opening displacement change. This degraded friction influences fatigue crack growth 
behavior by modifying the fiber cyclic constitutive law (10) in response to both the number of cycles and the crack opening displacement changes experienced at each point on the bridged crack surface. Interfacial degradation also directly influences the maximum fiber bridging strength attainable in a given load cycle via the monotonic constitutive law, $\sigma_{\mathrm{f}}(\delta)$, given by (I 1) and (I 2).

The non-uniform crack opening displacement in a flexural beam requires that the accumulated crack opening displacement change be a function of the position on the crack surface:

$\sum_{\mathrm{i}=1}^{\mathrm{N}} \Delta \delta_{\mathrm{i}}(\mathrm{x})=$ accumulated crack opening displacement change at $\mathrm{x}$.

This in turn means that the interfacial bond degradation is a function of the position on the crack surface. The bond strength degrades more near the crack mouth, since fibers are subjected to larger number of cycles and crack opening displacement changes, whereas the undegraded bond strength is exerted in the newly created crack surface near the crack tip.

\section{Fatigue Crack Growth Analysis}

Fatigue crack growth is simulated with the theoretical model described above and is compared to the data of a fatigue experiment of an FRC by Stang and Jun. ${ }^{4,5}$ Given the microstructural parameters of the tested FRC, fatigue crack growth can be simulated with the model applied to this particular experiment. A comparison of the simulated results with the test results provides confidence in the overall approach of the theoretical model. 


\section{Experiment}

The fatigue crack growth experiment ${ }^{4,5}$ is briefly summarized here. The tested FRC contained coarse aggregates of $8 \mathrm{~mm}$ maximum and was reinforced with 1 vol.\% hookedend steel fiber and 1vol.\% polypropylene fiber. The FRC beam with depth 100mm, thickness $50 \mathrm{~mm}$, and length $350 \mathrm{~mm}$ was loaded in three point flexural fatigue. Maximum loading level was $90 \%$ of the static flexural strength, and the ratio of the maximum to the minimum loading level was 0.2 . The FRC beam exhibited a stable crack growth during the first loading from zero to the maximum loading level, and this crack grew throughout the subsequent fatigue load cycles. The crack length was measured by fluorescent epoxy impregnation and ultra violet illumination when the fatigue test was interrupted at pre-set number of cycles. The first crack length determined was $55 \mathrm{~mm}$. The fatigue crack lengths determined were fairly long and ranged from 55 to $90 \mathrm{~mm}$ (Figure 6). Furthermore, the fatigue crack growth of this FRC was observed to have three distinct stages: initial decelerated growth $(0-0.2) \mathrm{N}_{\mathrm{f}}$, steady state growth $(0.2-0.7) \mathrm{N}_{\mathrm{f}}$, and final accelerated growth $(0.7-1.0) \mathrm{N}_{\mathrm{f}}$, where $\mathrm{N}_{\mathrm{f}}$ is the number of cycles to failure. Most of the fatigue life was observed to be spent in the second stage.

\section{Simulation}

The theoretical model presented in this paper is used to simulate the crack growth of the FRC tested by Stang and Jun., ${ }^{4,5}$ Input microstructural parameters required for the simulation are summarized in Tables 1 through 4 . Basis for parametric values chosen is discussed in the following order: matrix crack growth law, crack bridging, and interfacial degradation. 
Matrix fatigue crack growth law for cementitious materials has not been well determined, although experimental investigations have been carried out by three independent research groups. ${ }^{16-19}$ Their experimental crack growth curves were fitted to the Paris law which relates the crack growth rate to the crack tip stress intensity factor amplitude. Bulch et al. obtained the Paris law constant, $\mathrm{n}=3.12,3.12$, and 3.15 for three loading cases: $\mathrm{R}=0.1,0.2$, and 0.3 respectively. ${ }^{16}$ Bazant and Schell obtained $n=8.6$ for high strength concrete, ${ }^{19}$ and Bazant and $\mathrm{Xu}$ obtained $\mathrm{n}=10.6$ for normal strength concrete. ${ }^{18}$ Perdikaris et al. obtained $\mathrm{n}=14.0$ for concrete. ${ }^{17}$ The range of the determined values is large, and the Paris law does not fit the data of different loading cases, ${ }^{16}$ different specimen sizes, ${ }^{18,19}$ and different strengths. ${ }^{18,19}$ It is not clear if fatigue crack growth in concrete is dependent only on the crack tip stress intensity factor amplitude, $\Delta \mathrm{K}_{\text {tip }}$, or whether mean or maximum stress effect exists for fatigue crack growth. Therefore, future experimental investigations are needed for the determination of both fatigue crack growth law and its constants specific to cementitious materials. In this paper, the Paris constants, $\mathrm{C}$ and $\mathrm{n}$, for concrete are taken from Baluch et al. ${ }^{16}$ for $\mathrm{R}=0.2$ (Table 1 ).

Crack bridging stress is assumed to be exerted by aggregates and two types of fibers (hooked-end steel and polypropylene fibers), and is obtained by the superposition of these three bridging stresses. Each bridging stress can be obtained with the parameters given in Tables 2 through 4 and with the constitutive laws for monotonic and cyclic loading. Slip softening relation at the fiber-matrix interface under monotonic loading is used. ${ }^{32}$ The relation is given by

$$
\tau(\delta)= \begin{cases}\tau_{0} & \text { for } \delta \leq \delta^{*} \\ \tau_{0}+a_{1} \delta+a_{2} \delta^{2} & \text { for } \delta^{*}<\delta\end{cases}
$$


where $\tau_{0}=$ initial bond strength and, according to an experimental evaluation, ${ }^{33}$ the parameters $a_{1}$ and $a_{2}$ are reported to be -2 and 0 for hooked-end steel and are equal to zero for polypropylene.

Interfacial degradation test has been performed by Stang and Jun, ${ }^{30}$ but experimental characterization of interfacial degradation has just begun. Due to the lack of experimental data, the bond strength of both hooked-end steel and polypropylene fibers are assumed to degrade at the same rate, $r$. Hence,

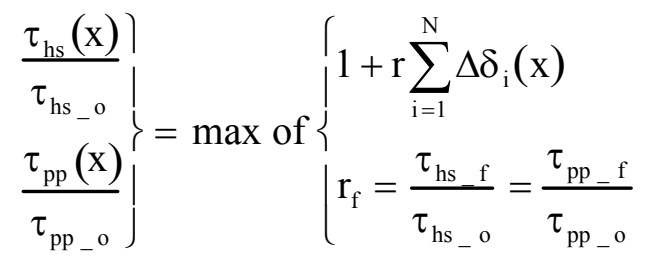

where subscripts hs and pp represent hooked steel and polypropylene fiber respectively, _o and _f represent initial and final steady state value, and $\mathrm{r}=\mathrm{a}_{\mathrm{hs}} / \tau_{\mathrm{hs} \_\mathrm{o}}=\mathrm{a}_{\mathrm{pp}} / \tau_{\mathrm{pp}_{\mathrm{o}} \mathrm{o}}$ (negative for degradation). $\mathrm{r}_{\mathrm{f}}=0.5$ is assumed in the current simulation.

\section{Results}

The static flexural test of the FRC beam is simulated using the microstructural parameters in Tables 2 through 4 . The static simulation is executed in a similar fashion to the fatigue simulation. Figure 5 shows the relation between the crack length and the equilibrium flexural stress. An initial unbridged flaw of $2 \mathrm{~mm}$ is assumed on the tension face of the beam, and the crack from the flaw develops in a stable manner up to the maximum flexural 
stress. The maximum flexural stress (the static flexural strength) is observed at a fairly long crack length due to crack bridging. At the maximum fatigue loading level, which is $90 \%$ of the static flexural strength, the crack length is $55 \mathrm{~mm}$ long which is the same length observed in the experiment. The experiment showed that the first cracking strength is 7.35MPa and the static flexural strength $9.46 \mathrm{MPa}$, and this agrees with the computed results.

The computed fatigue crack growth curve based on the integration of (2) is compared with the experimental data in Figure 6. The theoretical simulation successfully reproduces the three stages of crack growth observed in the experiment, and the degradation rate, $r,=-$ $0.0035 / \mathrm{mm}$ gives the number of cycles to failure measured in the experiment. The three distinct stages can be explained as follows. The crack tip stress intensity factor amplitude due to external applied loading, $\Delta \mathrm{K}_{\mathrm{a}}$, increases with the length of a crack emanating from the tension face and has an infinite value when the crack length is equal to the depth of the beam. At the same time, the magnitude of the crack tip stress intensity factor amplitude due to crack bridging, $\left|\Delta \mathrm{K}_{\mathrm{b}}\right|$, increases with the development of the bridging zone. Note that $\Delta \mathrm{K}_{\mathrm{b}}$ has a negative sign. The initial decelerated growth is caused by the effective reduction of the net crack tip stress intensity factor amplitude, $\Delta \mathrm{K}_{\text {tip }}$, due to the development of the bridging zone. The steady state growth is caused by the constant value of $\Delta K_{\text {tip }}$ when the increase of $\Delta K_{a}$ is balanced with the increase of $\left|\Delta K_{b}\right|$. The final accelerated growth eventually follows since, near the compression face, $\Delta \mathrm{K}_{\mathrm{a}}$ rapidly surpasses $\left|\Delta \mathrm{K}_{\mathrm{b}}\right|$.

Two discrepancies are seen in the comparison of the computed curve with the experimental data. First, the initial deceleration is overestimated in the simulation. Second, the final acceleration takes place rapidly in the simulation. The simulated crack growth in both the 
initial and final stages is closely related to the behavior of the interfacial bond degradation. It is possible that the interfacial bond degradation can be represented by a better function given by the superposition of two kinds of interfacial bond degradation for the two fibers in this hybrid FRC.

\section{Effect of degradation on fatigue crack growth}

Damage accumulation during fatigue crack growth is shown as decaying interfacial frictional bond strength along the crack surface in Figure 7. As the crack length increases by fatigue crack growth, interfacial frictional bond suffers from degradation. Degradation is most severe near the crack mouth where the largest accumulated crack opening displacement change is experienced. As expected, degradation is minimal near the crack tip because the newly created surface has not experienced a large value of accumulated crack opening displacement yet.

Fatigue crack growth with and without degradation is simulated with the theoretical model developed in this paper and is shown in Figure 8. Without degradation, fatigue crack is arrested at $64 \mathrm{~mm}$, and infinite fatigue life is predicted. This is because the net crack tip stress intensity factor amplitude, $\Delta \mathrm{K}_{\text {tip }}$, is effectively decreased to zero with the development of the bridging zone where fibers are not degraded.

The effect of different degradation rates on fatigue crack growth is also examined in Figure 8. It is seen for all three cases with degradation that the initial and final crack growth spend a small number of load cycles compared to the total fatigue life and that most of fatigue life is spent in the second steady state growth. The steady state crack growth is controlled by the net crack tip stress intensity factor amplitude, $\Delta \mathrm{K}_{\text {tip. }}$. With the higher degradation rate, 
the reduction in $\Delta \mathrm{K}_{\text {tip }}$ due to fiber bridging is smaller, so that the fatigue crack grows faster resulting in shorter fatigue life.

\section{Discussion}

\section{Design for high fatigue resistance}

Implications for the design of FRCs with high fatigue resistance can be obtained from the crack growth analysis. Crack growth curve has been observed to show the three stages: initial decelerated growth, steady state growth, and final accelerated growth. It is seen that most of fatigue life is spent in the second stage of steady state crack growth. If the crack growth rate during the steady state stage can be lowered, the total fatigue life can be made longer. With fiber bridging, it appears plausible to realize fatigue crack arrest during cyclic loading. In this case the total fatigue life becomes infinite. This can be achieved by minimizing the degradation rate of interfacial bond strength (Figure 8). Also other microstructural parameters have the same influence on crack growth. For example, increasing fiber volume fraction can lead to the slower growth rate in the steady state stage and eventually to crack arrest.

It is known in many materials ${ }^{6-8}$ that fatigue crack growth rate becomes negligible when the net crack tip stress intensity factor amplitude, $\Delta \mathrm{K}_{\text {tip }}$, is below a threshold value, $\Delta \mathrm{K}_{\mathrm{th}}$, so the above discussion on achieving negligible crack growth rate is equivalent to achieving $\Delta K_{\text {tip }}$ below $\Delta \mathrm{K}_{\text {th }}$. As mentioned above, $\Delta \mathrm{K}_{\mathrm{a}}$ increases with the crack length, so does $\Delta \mathrm{K}_{\mathrm{tip}}$, if $\Delta \mathrm{K}_{\text {tip }}$ is equal to $\Delta \mathrm{K}_{\mathrm{a}}$ without fiber bridging $\left(\Delta \mathrm{K}_{\mathrm{b}}=0\right) . \Delta \mathrm{K}_{\text {tip }}$ can be lowered to below $\Delta \mathrm{K}_{\text {th }}$ with the addition of fibers. This means that a properly designed FRC can arrest the fatigue crack even after the crack starts to grow, showing an advantage of FRCs. By contrast, concrete has no means to lower $\Delta \mathrm{K}_{\mathrm{th}}$, once a fatigue crack starts to grow. 
Fatigue limit is known to exist for many materials, especially for metals. Under the fatigue limit load level, virtually infinite number of load cycles can be applied without having fatigue failure, and this has been well demonstrated in the standard stress-life analysis (S-N analysis). It is reasonable that the fatigue limit can be connected to the threshold stress intensity factor amplitude, $\Delta \mathrm{K}_{\text {th }}$, since negligibly slower crack growth leads to virtually infinite life. Furthermore, it should be noted that the threshold stress intensity factor amplitude is a matrix property for fatigue crack activation which is independent of body geometry and loading mode.

Based on the discussions above, it appears possible to design an FRC member with high fatigue resistance that satisfies a given fatigue life requirement (either finite or infinite).

\section{Fiber bridging degradation as a fundamental material property}

Fiber bridging degradation can be treated as a fundamental material property which is specific to a given fiber composite. This property is the cycle-dependent relation between the bridging stress and the crack opening displacement, which governs the behavior of FRC structures under cyclic loading, and can be utilized in a similar manner that tensionsoftening properties are utilized for both theoretical and experimental investigations of FRCs under monotonic loading.

Theoretical investigation with fiber bridging degradation is necessary for a structural analysis of general FRC structures where cycle-dependent crack bridging is important. Experimental investigation is needed for the following three issues. First, fiber bridging degradation test can reveal the parameter which governs the degradation behavior. This 
will assess the validity of the concept of accumulated crack opening displacement change introduced in the current paper. Second, degradation mechanism can be revealed. Degradation can occur by interfacial bond degradation or fiber fatigue fracture, and this can be identified and understood more clearly by microscopic observation. Third, degradation behavior can be modified with the revealed mechanism. For example, interface modification by fiber surface treatment or matrix densification can modify the degradation behavior.

These investigations on fiber bridging degradation property can play some role of the conventional fatigue life tests (i.e. flexural fatigue tests), if the influence of the degradation on fatigue life is recognized more clearly. For example, fatigue life of different FRCs can be ranked based on their fiber bridging degradation behaviors without performing fatigue life tests. This becomes an advantage for an efficient material design process, in which both theoretical and experimental investigations are linked in a feed back loop.

\section{Conclusion}

A fatigue life model for short fiber reinforced brittle matrix composites has been developed based on the micromechanics of fiber bridging under cyclic loading. Fatigue crack growth simulation with this model has been compared to a fatigue experiment of an FRC, successfully reproducing the three stages of fatigue crack growth. In addition, the model produces results which are consistent with a wide body of knowledge concerned with fatigue limit in the standard S-N analysis and threshold stress intensity factor amplitude, $\Delta \mathrm{K}_{\mathrm{th}}$, in fatigue fracture experimental data. These comparisons provide added confidence to the validity of the general concepts behind the fatigue failure mechanism described, and 
these concepts underlie the construction of the present model. With further refinements, this model can serve as a prediction/design tool for fatigue life of FRCs.

The present study affords a theoretical foundation for understanding the role and effectiveness of fibers in extending fatigue life of concrete structures, which has been extensively demonstrated in the laboratory. ${ }^{34}$ Furthermore, the model suggests that even a small amount of fibers can lead to fatigue crack arrest, especially if interfacial degradation is limited. This may mean a use of fibers in concrete materials much more powerful than in many other mechanical properties.

The significance of fiber bridging degradation has been discussed. Fiber bridging degradation is present in fiber reinforced composites, and interfacial bond degradation is a possible source. The analysis in this paper shows that the degradation rate of interfacial bond strength significantly affects the fatigue life of FRCs. Therefore, it is necessary to measure interfacial bond degradation experimentally and to understand the mechanism of degradation.

Fiber bridging degradation can be treated as a fundamental material property. For concrete with known matrix properties, fiber bridging degradation tests based on uniaxial cyclic loading of cracked FRCs can replace some part of flexural fatigue tests which are timeconsuming with relatively large specimens. Development of high fatigue resistant FRCs can be made efficient based on the investigation of this property. The uniaxial cyclic constitutive relation is similar to the uniaxial tensile stress-crack opening relation which has been shown to be one of the most important fundamental properties governing a variety of FRC behaviors. ${ }^{32,35-37}$ 
Another implication of the present model is on efficient prediction of fatigue life of a structural member subjected to high frequency cyclic loading. Although the model calculations have been carried out for an FRC beam under flexural loading, the fundamental concept behind this fatigue model is widely applicable to other body geometry and loading configuration. Specifically, the weight function expressed in (7) will need to be modified for other than a flexural beam, with all other elements in the model remaining the same. For more complicated geometries where analytical weight functions are not available, the fundamental matrix fatigue crack growth concept, the cyclic constitutive bridging contribution from fibers, and the interfacial bond degradation concept described in this paper can still be applied, even if it is necessary to couple them with a finite element model.

In conclusion, the fatigue crack growth analysis of FRC described in this paper has implications on material design, on fatigue property characterization, and on prediction of fatigue life of FRC structural elements subjected to cyclic loading.

Finally the present study highlights two areas in which knowledge is severely deficient. In addition to interface bond degradation pointed out above, crack growth law for cementitious materials such as cement, mortar, and concrete needs to be investigated. Crack growth rate can be dependent on crack tip stress intensity factor amplitude, $\Delta \mathrm{K}_{\text {tip }}$, maximum crack tip stress intensity factor, $\mathrm{K}_{\max }$, or a combination of both. With the crack growth law that covers mean stress effect, a wide range of loading situations can be analyzed. 


\section{Acknowledgment}

This work has been supported by a grant from the National Science Foundation (MSS9301949) to the ACE-MRL at the University of Michigan, and by a NATO grant (930023) which supports collaboration research between the ACE-MRL and the Technical University of Denmark. Helpful discussions with Dr. B. N. Cox, Dr. H. Stang, and Z. Jun are gratefully acknowledged. We are indebted to Dr. B. N. Cox for providing us a numerical code for solving bridged crack problems, and to Dr. H. Stang for providing us unpublished experimental data. 


\section{References}

1. Binsheng, Z., Zhaohong, Z., \& Keru, W., Fatigue Rupture of Plain Concrete Analyzed by Fracture Mechanics. In Proc. SEM/RILEM International Conference on Fracture of Concrete and Rock, eds. S. P. Shah and S. E. Swartz, 1987, pp. 5863.

2. Ukrainczyk, V. \& Rak, Z., Post-Fatigue Properties of Steel Fiber Reinforced Concrete. In Fiber Reinforced Cement and Concrete, ed. R. N. Swamy, 1992, pp. $257-265$.

3. Perdikaris, P. C., Calomino, A. M., \& Chudnovsky, A., Effect of Fatigue on Fracture Toughness of Concrete. Journal of Engineering Mechanics, 112 (8) (1986) 776-791.

4. Jun, Z. \& Stang, H., Fatigue Performance in Flexure of Fiber Reinforced Concrete. Accepted for publication in ACI Materials Journal, (1996).

5. Stang, H. \& Jun, Z., Experimental Determination of Fatigue Crack Growth in Fiber Reinforced Concrete. In Recent Advances in Experimental Mechanics, eds. J. F. Silva Gomez et al., 1994, pp. 1347-1352.

6. Broek, D., Elementary Engineering Fracture Mechanics. Kluwer Academic Publishers, 1991.

7. Barsom, J. M. \& Rolfe, S. T., Fracture and Fatigue Control in Structures Applications of Fracture Mechanics. Prentice-Hall, 1987. 
8. Suresh, S., Fatigue of Materials. Cambridge University Press, 1991.

9. Kishimoto, H., Cyclic Fatigue in Ceramics. JSME International Journal, Series I, 34 (4) (1991) 393-403.

10. Holmes, J. W., Fatigue of Fiber-Reinforced Ceramic Composites. In Flight-Vehicle Materials, Structures and Dynamics Technologies - Assessment and Future Directions, eds A. K. Noor and F. L. Venneri, 3, 1992, pp. 193-238.

11. Han, L. X. \& Suresh, S., High-Temperature Failure of an Alumina-Silicon Carbide Composite under Cyclic Loads: Mechanisms of Fatigue Crack-Tip Damage. Journal of the American Ceramic Society, 72 (7) (1989) 1233-38.

12. Dauskardt, R. H., James, M. R., Porter, J. R., \& Ritchie, R. O., Cyclic FatigueCrack Growth in a SiC-Whisker-Reinforced Alumina Ceramic Composite: Longand Small-Crack Behavior. Journal of the American Ceramic Society, 75 (4) (1992) 759-771.

13. Dauskardt, R. H., Dalgleish, B. J., Yao, D., Ritchie, R. O., \& Becher, P. F., Cyclic Fatigue-Crack Propagation in a Silicon Carbide Whisker-Reinforced Alumina Composite: Role of Load Ratio. Journal of Materials Science, 28 (1993) 32583266.

14. Dauskardt, R. H., Cyclic Fatigue-Crack Growth in Grain Bridging Ceramics. Journal of Engineering Materials and Technology, 115 (1993) 244-251. 
15. Dauskardt, R. H., Marshall, D. B., \& Ritchie, R. O., Cyclic Fatigue-Crack Propagation in Magnesia-Partially-Stabilized Zirconia Ceramics. Journal of the American Ceramic Society, 73 (4) (1990) 893-903.

16. Baluch, M. H., Qureshy, A. B., \& Azad, A. K., Fatigue Crack Propagation in Plain Concrete. In Proc. SEM/RILEM International Conference on Fracture of Concrete and Rock, eds. S. P. Shah and S. E. Swartz, 1987, pp. 80-87.

17. Perdikaris, P. C. \& Calomino, A. M., Kinetics of Crack Growth in Plain Concrete. In Proc. SEM/RILEM International Conference on Fracture of Concrete and Rock, eds. S. P. Shah and S. E. Swartz, 1987, pp. 64-69.

18. Bazant, Z. P. \& Xu, K., Size Effect in Fatigue Fracture of Concrete. ACI Materials Journal, 88 (4) (1991) 390-399.

19. Bazant, Z. P. \& Schell, W. F., Fatigue Fracture of High-Strength Concrete and Size Effect. ACI Materials Journal, 90 (5) (1993) 472-478.

20. Paris, P. C. \& Erdogan, F., A Critical Analysis of Crack Propagation Laws. Journal of Basic Engineering, 85 (1963) 528-534.

21. Tada, H., The Stress Analysis of Cracks Handbook. Paris Prod. Inc., 1985.

22. Cox, B. N. \& Marshall, D. B., Stable and Unstable Solutions for Bridged Cracks in Various Specimens. Acta Metallurgica et Materialia, 39 (4) (1991) 579-589.

23. Wu, H. C., Matsumoto, T., \& Li, V. C., Buckling of Bridging Fibers in Composites. Journal of Materials Science Letters, 13 (1994) 1800-1803. 
24. Matsumoto, T. \& Li, V. C., Uniaxial Cyclic Behavior of Discontinuous Fiber Reinforced Composites. To appear in Proc. ASCE 4th Materials Engineering Conference, 1996.

25. Li, V. C., Postcrack Scaling Relations for Fiber Reinforced Cementitious Composites. Journal of Materials in Civil Engineering, 4 (1) (1992) 41-57.

26. Horii, H., Shin, H. C., \& Pallewatta, T. M., Mechanism of Fatigue Crack Growth in Concrete. Cement \& Concrete Composites, 14 (1992) 83-89.

27. Hordijk, D. A. \& Reinhardt, H. W., Growth of Discrete Cracks in Concrete under Fatigue Loading, In Proc. NATO Advanced Research Workshop, Toughening Mechanisms in Quasi-Brittle Materials, ed. S. P. Shah, 1990, pp. 553-568.

28. Stang, H., Evaluation of Properties of Cementitious Fiber Composite Materials. In Proc. International RILEM/ACI Workshop, High Performance Fiber Cement Composites, eds. H. W. Reinhardt and A. E. Naaman, 1992, pp. 388-406.

29. Evans, A. G., Zok, F. W., \& McMeeking, R. M., Fatigue of Ceramic Matrix Composites. Acta Metallurgica et Materialia, 43 (3) (1995) 859-875.

30. Stang, H. \& Jun, Z., Fiber Bridging Degradation Tests. unpublished data.

31. Walls, D. P., Bao, G., \& Zok, F. W., Mode I Fatigue Cracking in a Fiber Reinforced Metal Matrix Composite. Acta Metallurgica et Materialia, 41 (7) (1993) 20612071.

32. Li, V. C., Stang, H., \& Krenchel, H., Micromechanics of Crack Bridging in Fiber Reinforced Concrete. Materials and Structures, 26 (1993) 486-494.

33. Stang, H., Stress vs Crack Opening Relation. unpublished data. 
34. Ramakrishnan, V. \& Lokvik, B. J., Flexural Fatigue Strength of Fiber Reinforced Concretes. In High Performance Fiber Reinforced Cement Composites, eds H. W. Reinhardt and A. E. Naaman, 1992, pp. 271-287.

35. Cox, B. N., Extrinsic Factors in the Mechanics of Bridged Cracks. Acta Metallurgica et Materialia, 39 (6) (1991) 1189-1201.

36. Li, V. C., Mihashi, H., Alwan, J., Brinker, A., Horii, H., Leung, C., Stang, H., Maalej, M., \& Wu, H. C., Micromechanical Models of Mechanical Response of HPFRCC. In Pre-Proc. High Performance Fiber Reinforced Cement CompositesHPFRCC 95, 1995, pp. 43-95.

37. Li, V. C., Fiber Reinforced Cementitious Composites in Structural Design/Applications. In Proc. 4th Japan SAMPE International Symposium, 2, 1995, pp. 1340-1345.

38. Li, V. C., Wang, Y., \& Backer, S., Effect of Inclining Angle, Bundling, and Surface Treatment on Synthetic Fiber Pull-Out from a Cement Matrix. Journal of Composites, 21 (2) (1990) 132-140. 


\section{Appendix I: Fiber Bridging Monotonic/Cyclic Constitutive Law}

Fiber bridging monotonic constitutive law

The fiber bridging monotonic constitutive law, $\sigma_{\mathrm{f}}(\delta)$, is given in a normalized form derived by $\mathrm{Li}^{25}$ For pre-peak part,

$\tilde{\sigma}_{\mathrm{f}}(\tilde{\delta})=\mathrm{g}\left[2\left(\tilde{\delta} / \tilde{\delta}^{*}\right)^{\frac{1}{*}}-\left(\delta / \tilde{\delta}^{*}\right)\right] \quad$ for $0 \leq \tilde{\delta} \leq \tilde{\delta}^{*}$

where $\tilde{\sigma}_{\mathrm{f}}=\sigma_{\mathrm{f}} / \sigma_{\mathrm{o}}, \sigma_{\mathrm{o}}=\mathrm{V}_{\mathrm{f}} \tau\left(\mathrm{L}_{\mathrm{f}} / \mathrm{d}_{\mathrm{f}}\right) / 2, \mathrm{~V}_{\mathrm{f}}=$ fiber volume fraction, $\tau=$ interfacial frictional bond strength, $\mathrm{L}_{\mathrm{f}}=$ fiber length, $\mathrm{d}_{\mathrm{f}}=$ fiber diameter, $\mathrm{g}=2 /\left(4+\mathrm{f}^{2}\right)\left(1+\mathrm{e}^{\pi \mathrm{f} / 2}\right)$, $\mathrm{f}=$ snubbing coefficient, $\tilde{\delta}=\delta /\left(\mathrm{L}_{\mathrm{f}} / 2\right), \tilde{\delta}^{*}=\delta^{*} /\left(\mathrm{L}_{\mathrm{f}} / 2\right)=\left(2 \tau \mathrm{L}_{\mathrm{f}}\right) /\left(\mathrm{E}_{\mathrm{f}} \mathrm{d}_{\mathrm{f}}\right)$, and $\mathrm{E}_{\mathrm{f}}=$ fiber modulus.

For post-peak part,

$\tilde{\sigma}_{\mathrm{f}}(\tilde{\delta})=\mathrm{g}\left[1-\left(\delta-\tilde{\delta}^{*}\right)\right] \quad$ for $\tilde{\delta}^{*}<\tilde{\delta} \leq 1$

Fiber bridging cyclic constitutive law

The fiber bridging cyclic constitutive law, $\Delta \sigma_{\mathrm{f}}(\Delta \delta)$, was modeled by Matsumoto and $\mathrm{Li}^{24}$ with the use of the single fiber load-displacement relation during cyclic loading, $\Delta \mathrm{P}(\Delta \delta)$, derived previously by $\mathrm{Wu}$ et al. ${ }^{23}$

Fiber bridging stress change can be decomposed into those due to fibers in debonding and sliding in the preceding load cycle, and, in a normalized form, this is given by 
$\Delta \tilde{\sigma}_{\mathrm{f}}(\Delta \tilde{\delta})=\left.\Delta \tilde{\sigma}_{\mathrm{f}}\right|_{\text {debonding }}+\left.\Delta \tilde{\sigma}_{\mathrm{f}}\right|_{\text {sliding }}$

where $\Delta \tilde{\sigma}_{\mathrm{f}}=\Delta \sigma_{\mathrm{f}} / \sigma_{\mathrm{o}}$ and $\Delta \tilde{\delta}=\Delta \delta /\left(\mathrm{L}_{\mathrm{f}} / 2\right)$. The fiber bridging stress change due to fibers in debonding, $\left.\Delta \tilde{\sigma}_{\mathrm{f}}\right|_{\text {debonding }}$, is obtained by an integration with the assumption of $3 \mathrm{D}$ randomness in fiber orientation, $\phi$, and centroidal location, $z$, relative to crack plane. With $\mathrm{z}^{\prime}=\mathrm{z} /\left(\mathrm{L}_{\mathrm{f}} / 2\right)$, this is given by

$\left.\Delta \tilde{\sigma}_{\mathrm{f}}\right|_{\text {debonding }}=\frac{8}{\pi \tau\left(\frac{\mathrm{L}_{\mathrm{f}}}{\mathrm{d}_{\mathrm{f}}}\right) \mathrm{d}_{\mathrm{f}}^{2}} \int_{\phi=0}^{\frac{\pi}{2}} \int_{\mathrm{z}^{\prime}=0}^{\mathrm{z}_{\mathrm{o}} \cos \phi} \Delta \mathrm{P}_{1}(\Delta \delta) \mathrm{e}^{\mathrm{f} \phi} \sin \phi \mathrm{d} \mathrm{z}^{\prime} \mathrm{d} \phi$

where

$\Delta \mathrm{P}_{1}(\Delta \delta)=\pi \sqrt{\frac{\tau \mathrm{d}_{\mathrm{f}}^{3} \mathrm{E}_{\mathrm{f}} \Delta \delta}{2}}$.

The factor $\mathrm{e}^{\mathrm{f} \phi}$ in (I 4) refers to a snubbing effect $^{38}$ which describes the mechanical interactions between a loaded inclined fiber and a matrix material. The integration leads to

$\left.\Delta \tilde{\sigma}_{\mathrm{f}}\right|_{\text {debonding }}=\mathrm{g} 2 \sqrt{2}\left(\frac{\Delta \tilde{\delta}}{\tilde{\delta}_{\text {max }}}\right)^{\frac{1}{2}}\left(\frac{\tilde{\delta}_{\max }}{\tilde{\delta}^{*}}\right)^{\frac{1}{2}}\left(1-\left(\frac{\tilde{\delta}_{\max }}{\tilde{\delta}^{*}}\right)^{\frac{1}{2}}\right)$ 
where $\tilde{\delta}_{\max }=\delta_{\max } /\left(\mathrm{L}_{\mathrm{f}} / 2\right)$ and $\delta_{\max }=$ maximum crack opening displacement experienced in the preceding load cycle.

Similarly, the fiber bridging stress change due to fibers in sliding, $\left.\Delta \tilde{\sigma}_{\mathrm{f}}\right|_{\text {sliding }}$, is given by

$$
\begin{aligned}
\left.\Delta \tilde{\sigma}_{\mathrm{f}}\right|_{\text {sliding }}= & \frac{8}{\pi \tau\left(\frac{\mathrm{L}_{\mathrm{f}}}{\mathrm{d}_{\mathrm{f}}}\right) \mathrm{d}_{\mathrm{f}}^{2}} \int_{\phi=0}^{\frac{\pi}{2}} \int_{\mathrm{z}^{\prime}=\mathrm{z}_{\mathrm{o}} \cos \phi}^{\left(1-\tilde{\delta}_{\max }\right) \cos \phi} \Delta \mathrm{P}\left(\Delta \delta, \delta_{\max }\right)\left(=\text { the smaller of }\left\{\begin{array}{l}
\Delta \mathrm{P}_{2} \\
\Delta \mathrm{P}_{3}
\end{array}\right\}\right) \\
& \mathrm{e}^{\mathrm{f} \phi} \sin \phi \mathrm{dz} \mathrm{z}^{\prime} \mathrm{d} \phi
\end{aligned}
$$

where

$$
\begin{aligned}
& \Delta \mathrm{P}_{2}\left(\Delta \delta, \delta_{\max }\right)=-\frac{3}{2} \pi \tau \mathrm{d}_{\mathrm{f}}\left(\delta_{\text {max }}-\delta_{\mathrm{o}}\right)+\sqrt{\frac{9}{4} \pi^{2} \tau^{2} \mathrm{~d}_{\mathrm{f}}^{2}\left(\delta_{\max }-\delta_{\mathrm{o}}\right)^{2}+\frac{\pi^{2} \tau \mathrm{d}_{\mathrm{f}}^{3} \mathrm{E}_{\mathrm{f}} \Delta \delta}{2}},(\mathrm{I} 8) \\
& \Delta \mathrm{P}_{3}\left(\Delta \delta, \delta_{\text {max }}\right)=\pi \tau \mathrm{d}_{\mathrm{f}} \Delta \delta+2 \mathrm{P}_{\max }-\frac{4 \mathrm{P}_{\max }}{\pi \mathrm{d}_{\mathrm{f}}^{2} \mathrm{E}_{\mathrm{f}}}\left(3 \mathrm{P}_{\mathrm{o}}-\mathrm{P}_{\text {max }}\right),
\end{aligned}
$$

$\delta_{\mathrm{o}}=\left(4 \tau l^{2}\right) /\left(\mathrm{E}_{\mathrm{f}} \mathrm{d}_{\mathrm{f}}\right)$ is the crack opening displacement at which debonding is completed, $l=$ fiber embeddment length, $\mathrm{P}_{\max }=\pi \tau \mathrm{d}_{\mathrm{f}}\left(l-\delta_{\max }+\delta_{\mathrm{o}}\right)$, and $\mathrm{P}_{\mathrm{o}}=\pi \tau \mathrm{d}_{\mathrm{f}} l$. The integration is solved by choosing the smaller of $\Delta \mathrm{P}_{2}$ and $\Delta \mathrm{P}_{3}$ numerically.

\section{Appendix II: Aggregate Bridging Monotonic/Cyclic Constitutive Law}

The aggregate bridging monotonic constitutive law is given by an empirical equation proposed by Stang. ${ }^{28}$ The aggregate bridging stress, $\sigma_{\mathrm{m}}$, as a function of the crack opening displacement, $\delta$, is given by 
$\sigma_{\mathrm{m}}(\delta)=\frac{\sigma_{\mathrm{m}}^{\mathrm{u}}}{1+\left(\frac{\delta}{\delta_{\mathrm{o}}}\right)^{\mathrm{p}}}$

where $\sigma_{\mathrm{m}}^{\mathrm{u}}=$ maximum aggregate bridging stress at $\delta=0, \delta_{\mathrm{o}}=$ crack opening displacement which corresponds to the half of $\sigma_{\mathrm{m}}^{\mathrm{u}}$, and $\mathrm{p}$ describes the shape of the bridging curve (Figure 4).

The aggregate bridging cyclic constitutive law is simply given by

$\Delta \sigma_{\mathrm{m}}(\Delta \delta)=\frac{\sigma_{\mathrm{m} \max }}{\delta_{\max }} \Delta \delta$

where $\left(\delta_{\max }, \sigma_{\mathrm{m} \max }\right)$ is the point at which unloading occurs. 


\section{Figure Captions}

Figure 1 Fatigue damage on material constituents

Figure 2 Fiber bridging stress-crack opening displacement (COD) relation (constitutive law) for pre-peak. ${ }^{24}$

Figure 3 Fiber bridging stress-crack opening displacement (COD) relation (constitutive law) for post-peak. ${ }^{24}$

Figure 4 Aggregate bridging stress-crack opening displacement relation (constitutive law).

Figure 6 Comparison between fatigue crack growth measured ${ }^{5}$ and theoretical simulation with different degradation rates.

Figure 7 Degradation development with the increasing crack length. Insert shows the magnification at the crack tip.

Figure 8 Fatigue crack growth curves with different degradation rates and without degradation. 
Table 1 Paris law constants. ${ }^{16}$

\begin{tabular}{lll}
\hline Paris constant & $\mathrm{C}$ & $\mathrm{n}$ \\
\hline concrete & $9.0310^{-6}$ & 3.12 \\
\hline
\end{tabular}

Table 2 Fiber parameters. ${ }^{4,5}$

\begin{tabular}{lllll}
\hline Fiber & $\mathrm{L}_{\mathrm{f}}(\mathrm{mm})$ & $\mathrm{E}_{\mathrm{f}}(\mathrm{GPa})$ & $\mathrm{d}_{\mathrm{f}}(\mu \mathrm{m})$ & $\mathrm{V}_{\mathrm{f}}(\%)$ \\
\hline hooked steel & 30 & 210 & 500 & 1 \\
polypropylene & 12 & 12 & 48 & 1 \\
\hline
\end{tabular}

Table 3 Interface parameters. ${ }^{32,33}$

\begin{tabular}{llll}
\hline Interface & $\mathrm{f}$ & $\tau_{\mathrm{o}}(\mathrm{MPa})$ & \\
\hline hooked steel & 0.75 & 4.5 & $\mathrm{a}_{1}=-2, \mathrm{a}_{2}=0$ \\
polypropylene & 0 & 0.8 & $\mathrm{a}_{1}=\mathrm{a}_{2}=0$ \\
\hline
\end{tabular}

Table 4 Matrix parameters (*: assumed value). ${ }^{32}$

\begin{tabular}{llllll}
\hline Matrix & $\mathrm{E}_{\mathrm{m}}(\mathrm{GPa})$ & $\sigma_{\mathrm{m}}^{\mathrm{u}}(\mathrm{MPa})$ & $\mathrm{p}$ & $\delta_{\mathrm{o}}(\mathrm{mm})$ & $\mathrm{K}_{\mathrm{c}}(\mathrm{MPa} \sqrt{\mathrm{m}})$ \\
\hline 30 & $2.8^{*}$ & 1.2 & 0.015 & $0.5 *$ \\
\hline
\end{tabular}




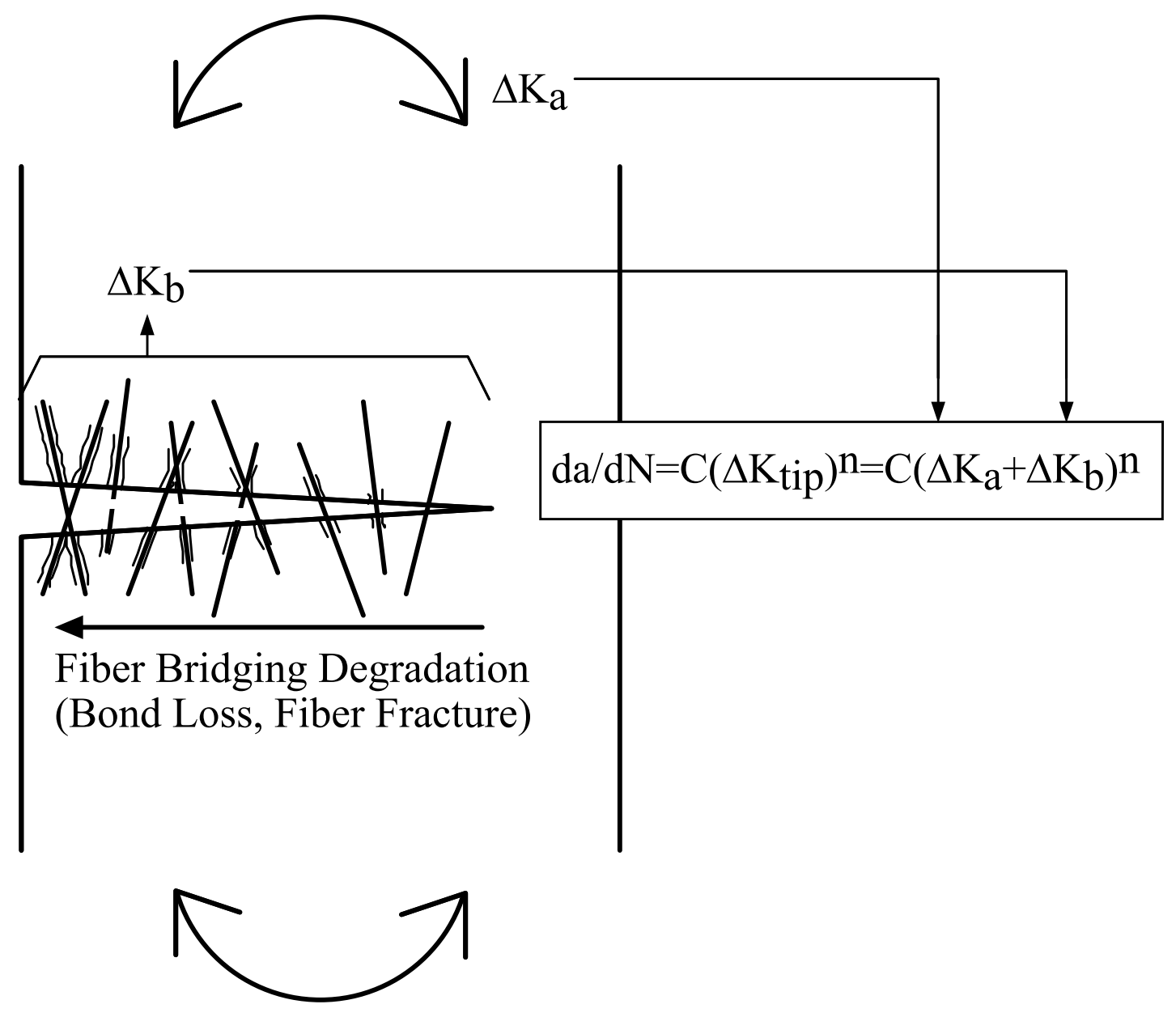

Figure 1 Fatigue damage on material constituents. 


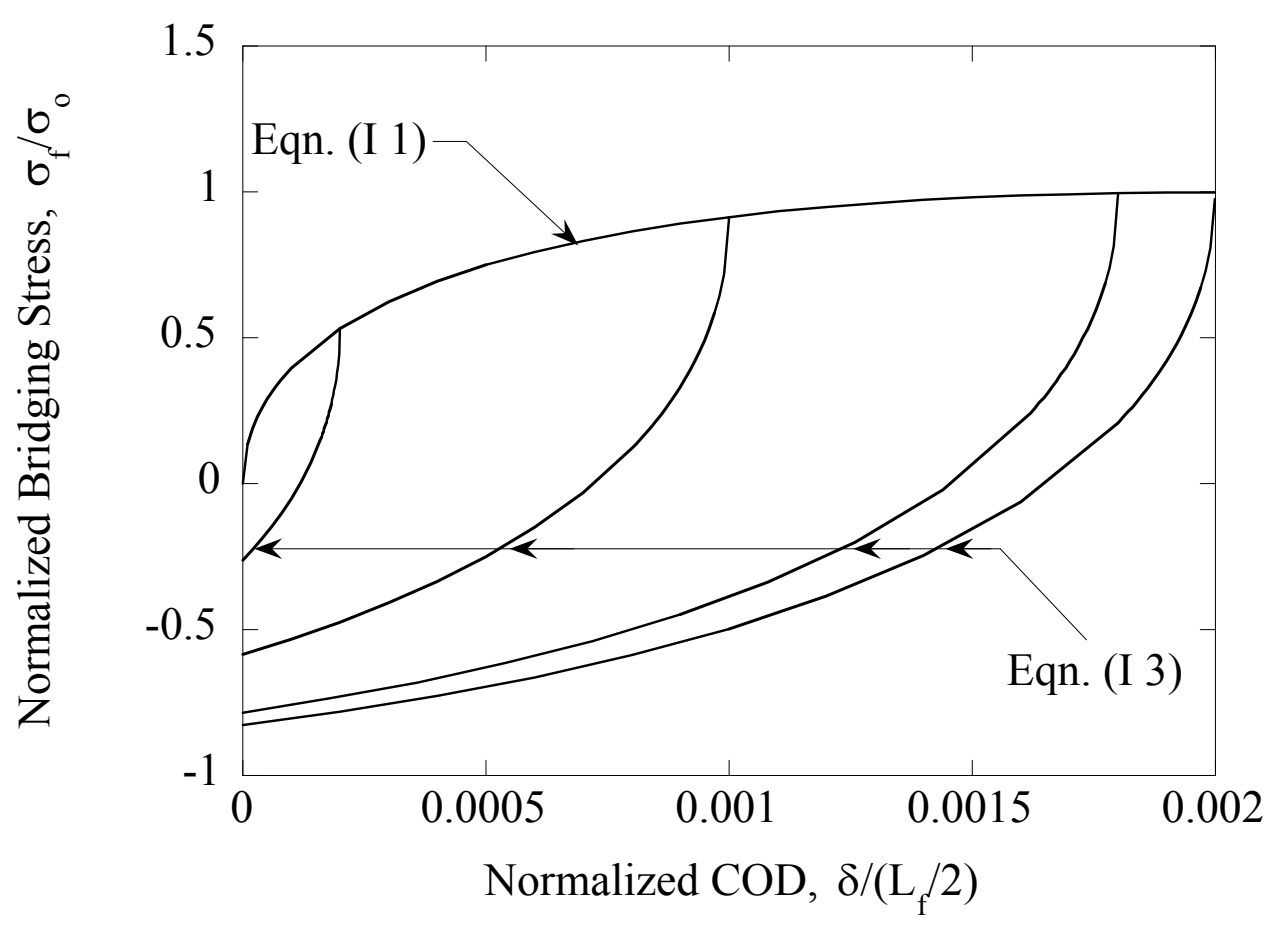

Figure 2 Fiber bridging stress-crack opening displacement (COD) relation (constitutive law) for pre-peak. ${ }^{24}$ 


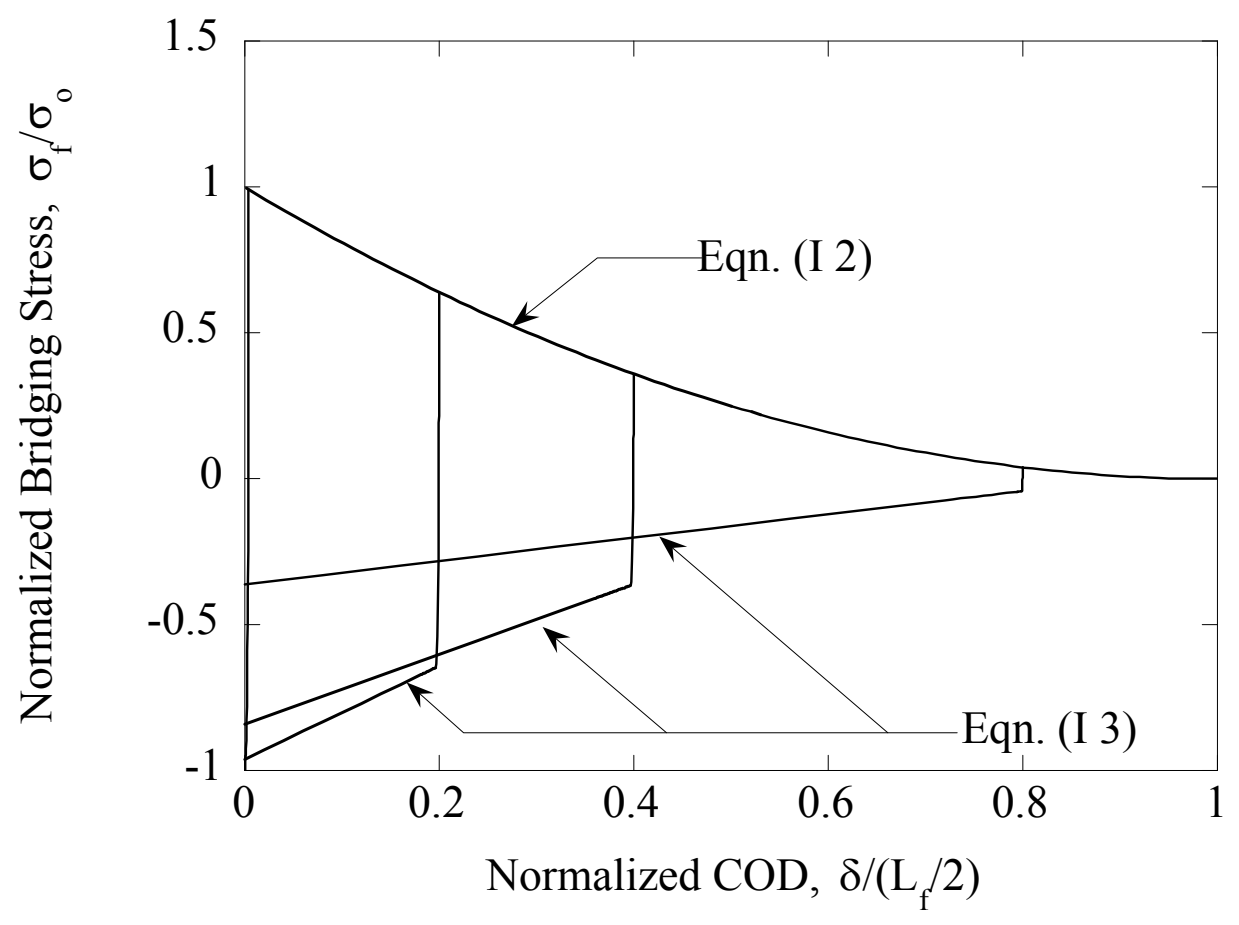

Figure 3 Fiber bridging stress-crack opening displacement (COD) relation (constitutive law) for post-peak. ${ }^{24}$ 


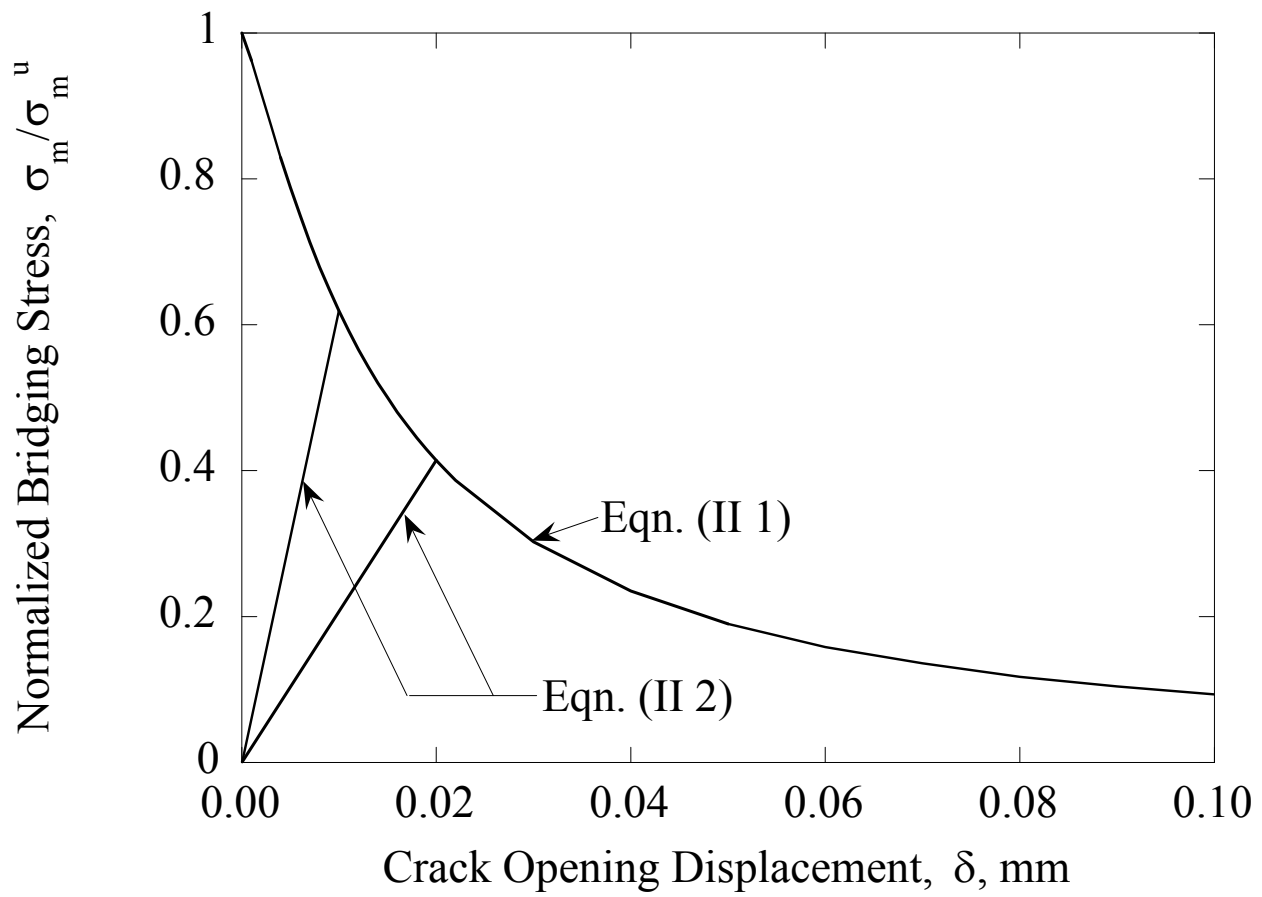

Figure 4 Aggregate bridging stress-crack opening displacement relation (constitutive law). 


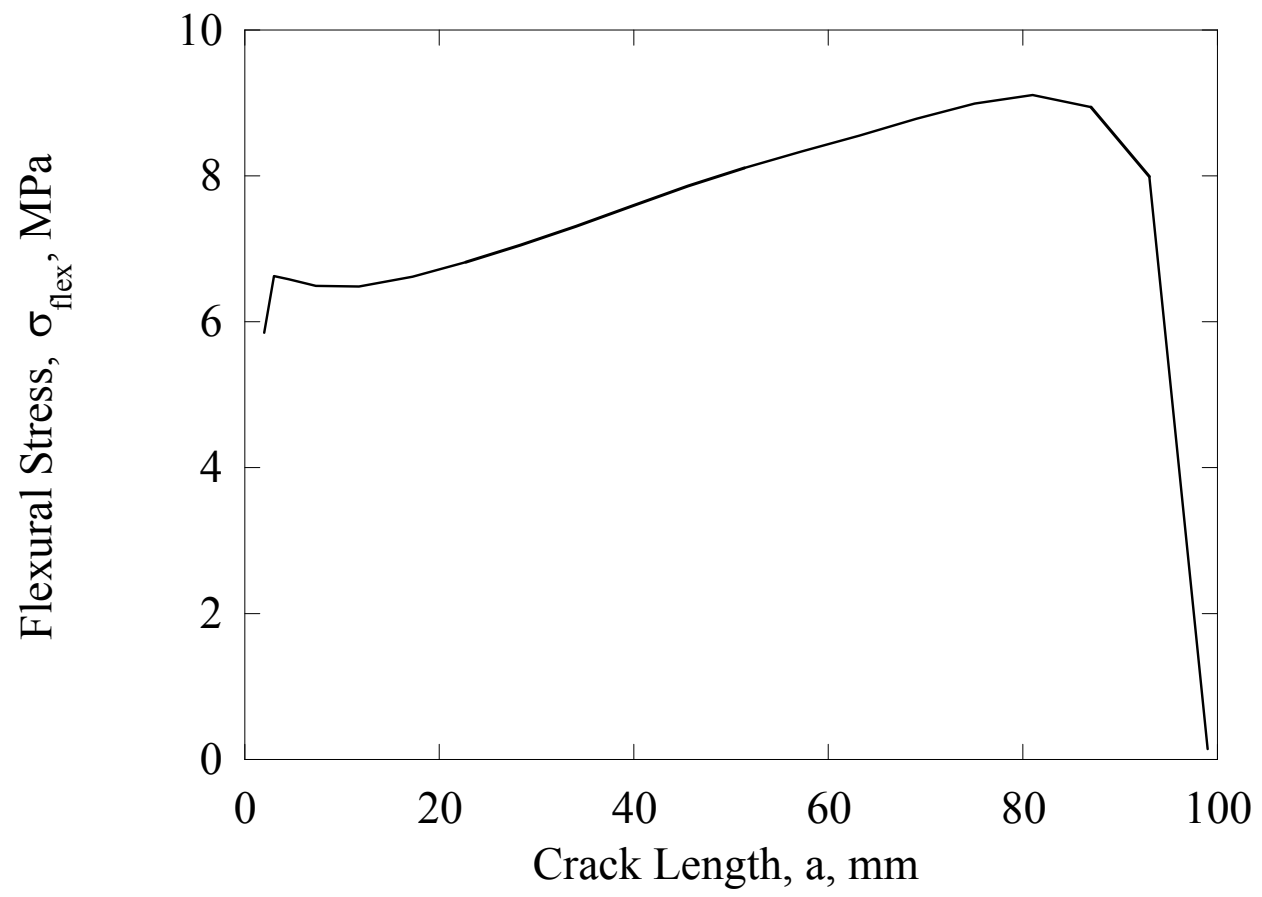

Figure 5 Crack length vs equilibrium flexural stress. 


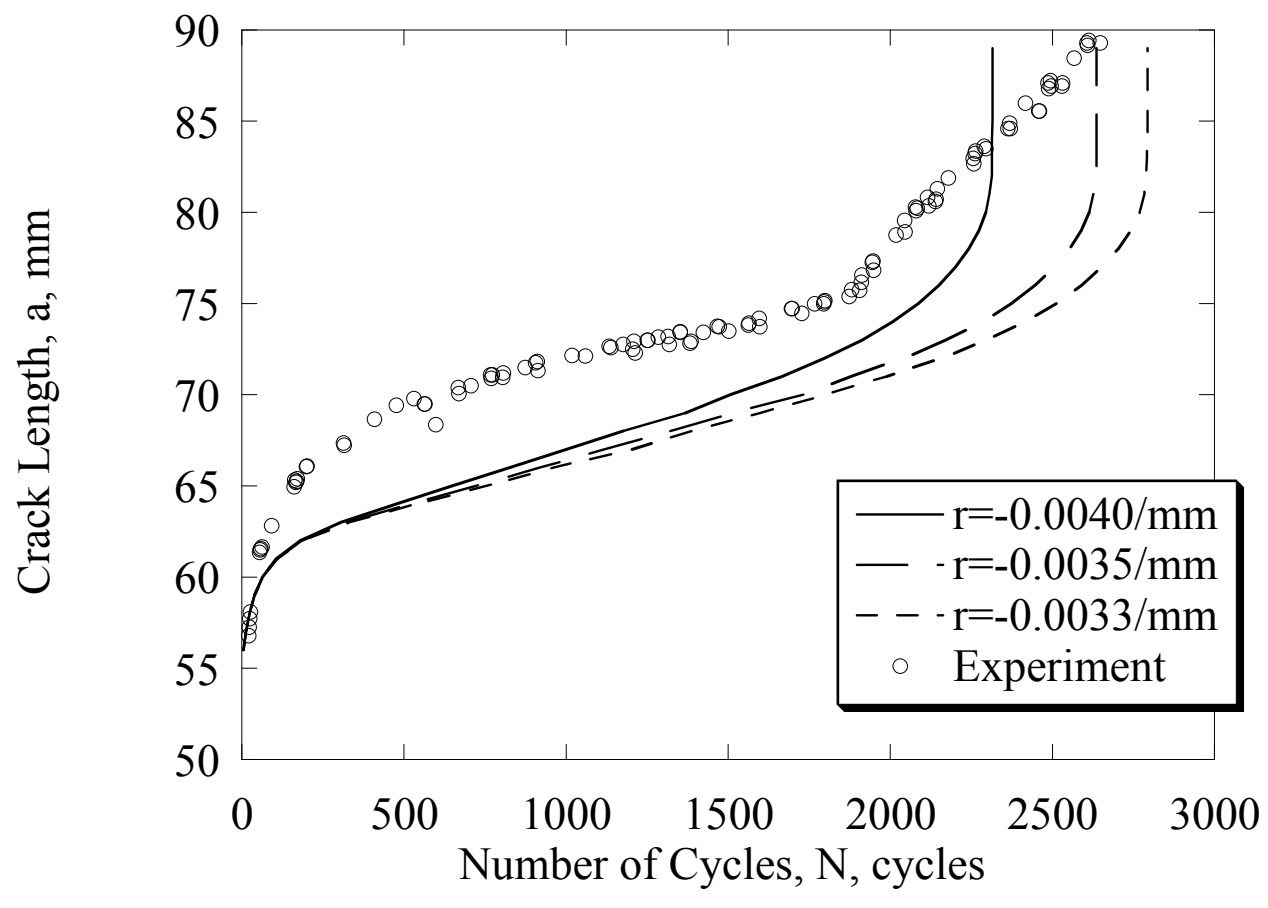

Figure 6 Comparison between fatigue crack growth measured ${ }^{5}$ and theoretical simulation with different degradation rates. 


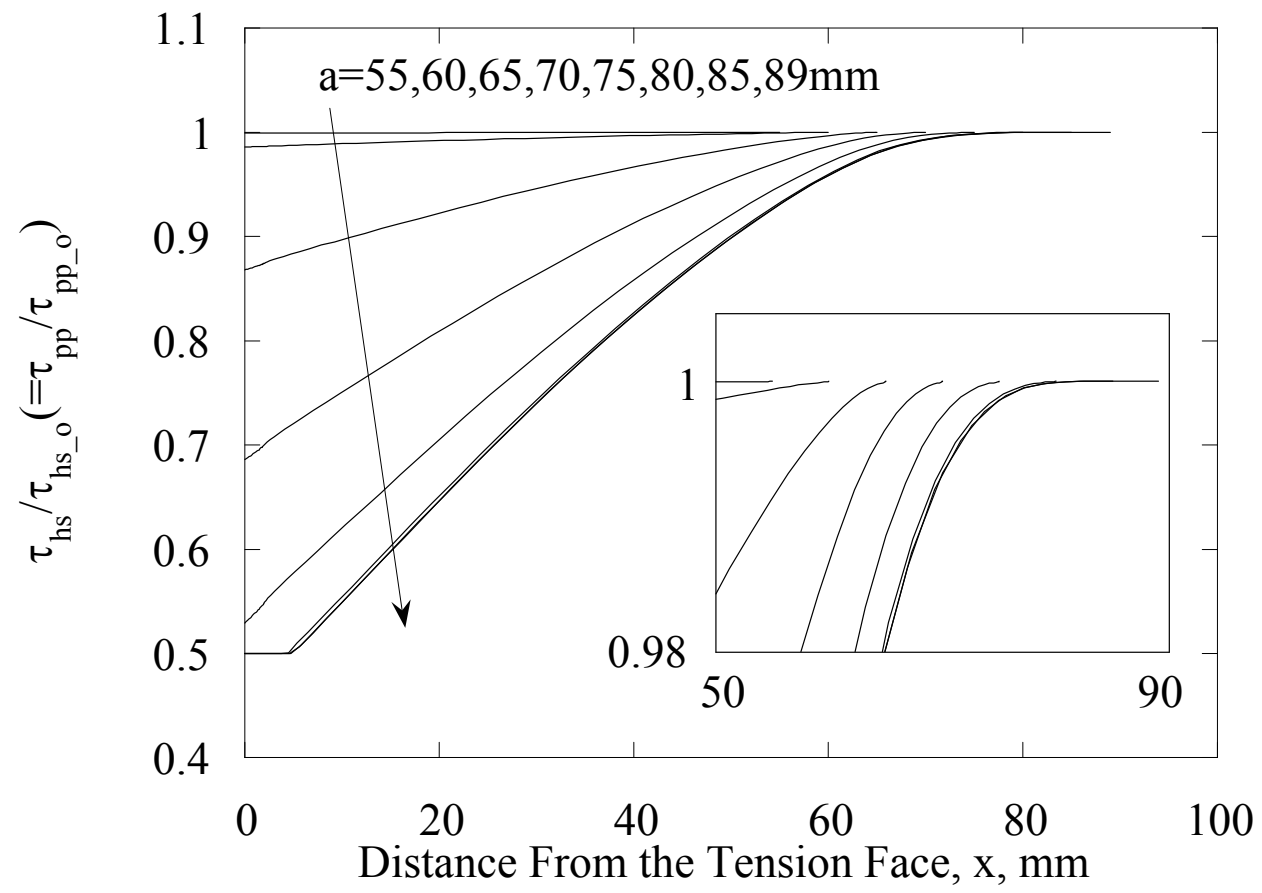

Figure 7 Degradation development with the increasing crack length. Insert shows the magnification at the crack tip. 


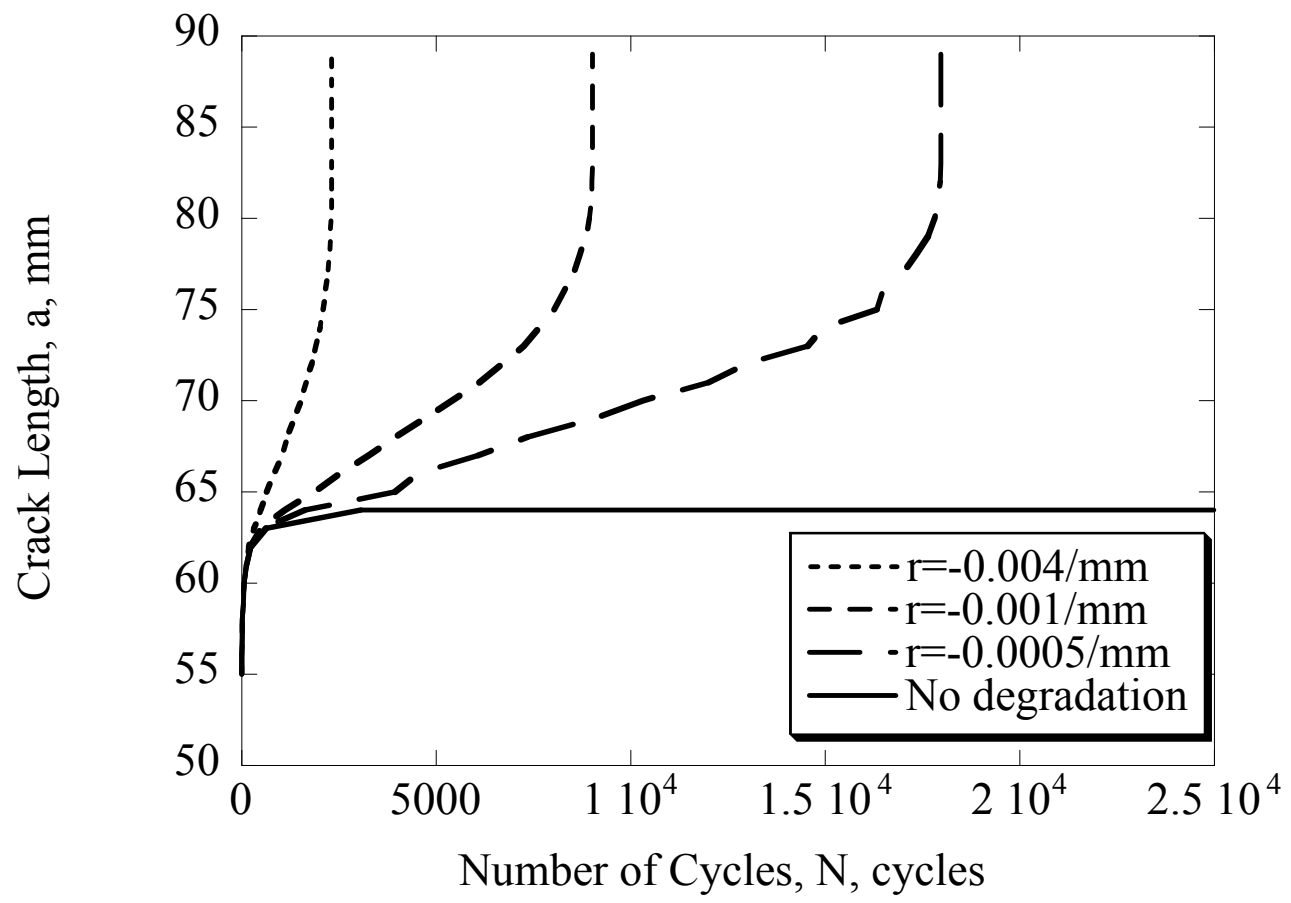

Figure 8 Fatigue crack growth curves with different degradation rates and without degradation. 